\title{
Validation and Reliability of the Thai version of the Food Allergy Quality of Life Questionnaire-Parent Form (FAQLQ-PF)
}

\author{
Wannaporn Limpitikul, ${ }^{1}$ Witchaya Srisuwatchari, ${ }^{1}$ Orathai Jirapongsananuruk,${ }^{1}$ Nualanong Visitsunthorn, ${ }^{1}$ Punchama Pacharn ${ }^{1}$
}

\begin{abstract}
Background: Food allergy has an impact on the quality of life of both patients and caregivers. It is, therefore, important to have a native language survey to evaluate health-related quality of life (HRQL) among food allergic children.

Objective: To translate the Food Allergy Quality of Life Questionnaire-Parent Form (FAQLQ-PF) to Thai language, and to validate this tool in Thai parents with food allergic children.

Methods: The FAQLQ-PF was translated into Thai language according to WHO guideline. The FAQLQ-PF Thai version was then administered to the parents of food allergic Thai children aged 0-12 years. The FAQLQ-PF Thai version was then readministered to those same parents 10-14 days after they first completed this assessment tool. Internal consistency by Cronbach's $\alpha$ and test-retest reliability by intraclass correlation coefficient (ICC) were assessed. The discriminant validity of the questionnaire was also evaluated.
\end{abstract}

Results: Ninety parents of participants answered the FAQLQ-PF Thai version. Of those, 9 parents (10\%) incompletely answered the first questionnaire. The FAQLQ-PF Thai version showed good internal consistency (Cronbach's $\alpha \geq 0.799$ ), but the test-retest reliability was only fair (ICC > 0.6). Factors that adversely affected the quality of life of Thai children with food allergy included age, presence of anaphylaxis, frequency of reactions, and the number of implicated foods. Patients with wheat allergy were negatively impacted in all domains of quality of life, whereas those with shellfish allergy had only emotional impact.

Conclusion: The FAQLQ-PF Thai version is a reliable and valid tool for assessing HRQL in Thai children with food allergy.

Key words: Questionnaire, Thai, quality of life, Food hypersensitivity, Pediatrics

\section{From:}

Division of Allergy and Immunology, Department of Pediatrics, Faculty of Medicine Siriraj Hospital, Mahidol University, Bangkok, Thailand

\section{Introduction}

Food allergy is a health problem that that has been increasing in prevalence over the last few decades, especially in children. ${ }^{1}$ According to the Centers of Disease Control and Prevention (CDC), the prevalence of food allergies increased among children aged 0-17 years in the United States from 3.4\% in $1997-1999$ to $5.1 \%$ in $2009-2011 .^{2}$ Data from food allergy questionnaires revealed a prevalence of adverse food reactions in Thai children that increased from $6.25 \%$ in 2005 to $9.3 \%$ in $2012 .{ }^{3,4}$ Children with food allergy can present with clinical

\author{
Corresponding author: \\ Punchama Pacharn \\ Division of Allergy and Immunology, Department of Pediatrics \\ Faculty of Medicine Siriraj Hospital, Mahidol University \\ 2 Prannok Road, Bangkoknoi, Bangkok 10700, Thailand \\ E-mail: punchama@gmail.com
}

manifestations that involve one or more systems, including cutaneous, respiratory, gastrointestinal, and/or cardiovascular, or even as life threatening conditions, such as anaphylaxis. ${ }^{5}$ Food allergy can cause psychological distress and impaired quality of life for both patients and their families. ${ }^{6-8}$ The common causes of food allergy in children include milk, egg, and wheat, and all of these foods contain essential nutrients. Therefore, children with food allergy are at higher risk for growth impairment than their non-food allergic counterparts. 
The quality of life of caregivers is adversely affected by limitations to family/social activities, more time needed for meal preparation, and stress relating to concerns about their child's health. ${ }^{8,9}$

Health related quality of life (HRQL) is an important index in patients with chronic illness, such as food allergy, asthma, or epilepsy. ${ }^{10-12}$ Tools designed to assess HRQL can be used to evaluate both the physical and psychological burdens of food allergy.

There are both generic and disease-specific questionnaires that can be used to assess HRQL. However, the generic HRQL questionnaires have less sensitivity for detecting changes in the quality of life of food allergic patients overtime or after intervention and treatment. ${ }^{13}$ As a result, disease-specific HRQL questionnaires for food allergic children were developed and validated, such as The Food Allergy Quality of Life-Parental Burden Questionnaire (FAQL-PB), ${ }^{8}$ which is completed by parents; and, the Food Allergy Quality of Life QuestionnaireChild Form (FAQLQ-CF), ${ }^{14}$ which is completed by children. However, the weaknesses and limitations of food allergy quality of life questionnaires designed to be completed by children include the limited language ability of children, and their potential lack of perception, awareness, and comprehension. ${ }^{15,16}$ These limitations influenced the development of a food allergy quality of life questionnaire for children-parent form. ${ }^{17,18}$ The objective was to develop a tool that could determine the food allergy-related HRQL of the child using data communicated from the parent. As part of the EuroPrevall Project, the Food Allergy Quality of Life Questionnaire-Parent Form (FAQLQ-PF) was developed and validated, ${ }^{17,18}$ and it has been used in both the United States and Europe. ${ }^{19}$ This questionnaire has been linguistically and culturally translated into many languages, including Spanish, ${ }^{20}$ Portuguese, ${ }^{21}$ and Japanese. ${ }^{22}$

In Thailand, there is currently no food allergy-specific HRQL questionnaire for food allergic children that is reported by their parents. Accordingly, the aim of this study was to lingually and culturally translate the Food Allergy Quality of Life Questionnaire-Parent Form (FAQLQ-PF) from English language to Thai language, and then to validate the FAQLQPF Thai version in Thai parents with food allergic children.

\section{Methods \\ Questionnaires}

The Food Allergy Quality of Life Questionnaire-Parent Form (FAQLQ-PF) was translated to Thai language according to World Health Organization (WHO) recommendations. ${ }^{23}$ First, the original version of the tool was forward translated from English to Thai. Second, the Thai translation of the questionnaire was reviewed by experts and changes were made, as needed. Third, the Thai version was backward translated from Thai to English by native English speaker, and that English version was compared with the original English language version. Fourth, the Thai version was subjected to evaluation by pretesting and cognitive interviewing among a small sample group of 20 people and revisions were once again made, as needed. Fifth, the final Thai version of the questionnaire was evaluated and approved by a group of experts.
The FAQLQ-PF questionnaire includes sections A, B, C and D. Parents of children in the 0-3 years age group answer parts $A$ and $B$; parents of patients in the 4-6 years age group answer parts $A, B$, and $C$; and, parents of those in the 7-12 years age group answer all 4 sections. Furthermore, there are 3 different domains that assess the impact of food allergy on HRQL in the FAQLQ-PF questionnaire. These domains are emotional impact (EI), food anxiety (FA), and social and dietary limitation (SDL). The EI domain reflects psychological phenomena, such as feelings of frustration and feeling different from other children. The FA domain reflects anxiety relating to food, such as being afraid to try new foods. The SDL domain reflects everyday dietary and social restrictions, such as the inability to take part in events involving food.

\section{Study population}

Parents of patients with a history of food allergy and who were followed-up at the pediatric allergy outpatient clinic of Siriraj Hospital, Mahidol University were recruited. Thai language literate parents of patients aged 0-12 years with previously diagnosed with food allergy by allergists were eligible for inclusion. Parents of patients with comorbid diseases that can impact quality of life, such as cardiac disease or chronic kidney disease, were excluded. The same questionnaire was sent to the same parents 10-14 days after the questionnaire was first administered during enrollment, and the completed questionnaire was returned by mail. The study protocol was approved by the Siriraj Institutional Review Board (SIRB) (COA no. Si 524/2018). Written informed consent was obtained from a parent or legal guardian of each child, and assent was obtained from all patients aged older than 7 years.

\section{Statistical analysis}

The raw FAQLQ-PF Thai version scores 0-6 were recorded as $1-7$, which is the same as the original version. The statistical program used for recording and analysis was SPSS version 18.0.

\section{Feasibility}

The percentage of the FAQLQ-PF Thai version questionnaires that were fully and accurately completed by respondents demonstrated the feasibility of the questionnaire.

\section{Reliability and internal consistency}

Reliability was evaluated using intraclass correlation coefficient (ICC). The test-retest method was performed by comparing the score of the FAQLQ-PF questionnaire when it was administered during the enrollment period with the score when it was readministered to the same person 10-14 days later. Internal consistency was assessed using Cronbach's alpha (a).

\section{Discriminant validity}

Independent t-test and one-way analysis of variance (ANOVA) were used to evaluate the discriminant validity of the questionnaire. The clinical and epidemiological characteristics of participants were assessed if they affected the global FAQLQ-PF score and all of the different domains. Differences between gender, age, manifestation, presence of anaphylaxis, 
the number of foods implicated, the frequency of reactions, and the type of treatment [oral immunotherapy (OIT) vs. food avoidance] were evaluated.

\section{Results}

The parents of 90 participants aged from 0-12 years (median 5.08 years) met the inclusion criteria. The age of participants was classified into the following 3 groups: 0-3 years (30 participants), 4-6 years (30 participants), and 7-12 years (30 participants). The demographic and clinical characteristics of these patients and caregivers are presented in Table $\mathbf{1 .}$ There were 9 parents (10\%) that incompletely answered the first questionnaire. However, these incomplete questionnaires were not excluded from the study. The same questionnaire was sent to the same parents within 10-14 days after they first answered the FAQLQ-PF Thai version.

Table 1. Demographic and clinical characteristics of the study population $(\mathrm{N}=90)$

\section{Characteristics}

n (\%)

Sex

Male

$45(50.0 \%)$

Female $45(50.0 \%)$

Age of onset (years)

$\begin{array}{lc}0-3 & 68(75.6 \%) \\ 4-6 & 13(14.4 \%) \\ 7-12 & 9(10.0 \%)\end{array}$

Type of reaction

$\begin{array}{lc}\text { Urticaria/angioedema } & 58(64.4 \%) \\ \text { Anaphylaxis } & 22(24.4 \%) \\ \text { Atopic dermatitis } & 13(14.4 \%) \\ \text { Allergic proctocolitis } & 5(5.6 \%) \\ \text { Food Protein Induced Enterocolitis Syndrome } & 2(2.2 \%)\end{array}$

Symptoms

Cutaneous

$86(95.6 \%)$

Respiratory

$49(54.4 \%)$

Gastrointestinal

$28(31.1 \%)$

Cardiovascular

$12(13.3 \%)$

\section{Number of allergic foods}

$\begin{array}{ll}\text { Single } & 41(45.6 \%) \\ \text { Multiple } & 49(54.5 \%)\end{array}$

Food

$\begin{array}{ll}\text { Shellfish } & 42(46.7 \%) \\ \text { Wheat } & 34(37.8 \%) \\ \text { Egg } & 29(32.2 \%) \\ \text { Milk } & 29(32.2 \%)\end{array}$

Table 1. (Continued)

\section{Food (Continued)}

\begin{tabular}{lc} 
Soy & $15(16.7 \%)$ \\
Treenuts & $14(15.6 \%)$ \\
Peanut & $11(12.2 \%)$ \\
Fish & $9(10.0 \%)$ \\
Fruits & $7(7.8 \%)$ \\
Vegetables & $3(3.3 \%)$ \\
Sesame & $3(3.3 \%)$ \\
Others & $8(8.9 \%)$ \\
Treatment & $84(93.3 \%)$ \\
Avoidance & $6(6.7 \%)$ \\
\hline Oral immunotherapy & \\
\hline
\end{tabular}

\section{Reliability}

Sixty-seven parents answered the FAQLQ-PF Thai version twice. Reliability was analyzed for the 3 different age groups, and for the different domains of the FAQLQ-PF Thai version, including emotional impact (EI), food anxiety (FA), and social and dietary limitation (SDL). Intraclass correlation coefficient (ICC) for the $0-3,4-6$, and 7-12 year age group was 0.868 , 0.604 , and 0.811 , respectively. The ICC for the global score and for all 3 domains showed higher than 0.75 in both the $0-3$ and 7-12 age groups (Table 2).

Table 2. Reliability and internal consistency of the Thai version of the Food Allergy Quality of Life Questionnaire-Parent Form (FAQLQ-PF)

\begin{tabular}{lcccc}
\hline Score & $\begin{array}{c}\text { Age } \\
\text { group }\end{array}$ & Mean \pm SD & Cronbach's $\alpha$ & ICC \\
\hline Global & $0-3$ & $3.5 \pm 1.4$ & 0.951 & 0.868 \\
& $4-6$ & $3.8 \pm 1.1$ & 0.927 & 0.604 \\
& $7-12$ & $4.4 \pm 1.5$ & 0.967 & 0.811 \\
\hline EI & $0-3$ & $3.4 \pm 1.5$ & 0.875 & 0.816 \\
& $4-6$ & $3.9 \pm 1.1$ & 0.799 & 0.520 \\
& $7-12$ & $4.5 \pm 1.5$ & 0.919 & 0.832 \\
\hline FA & $0-3$ & $4.3 \pm 1.7$ & 0.867 & 0.828 \\
& $4-6$ & $4.2 \pm 1.3$ & 0.854 & 0.626 \\
& $7-12$ & $4.7 \pm 1.5$ & 0.900 & 0.777 \\
\hline SDL & $0-3$ & $3.4 \pm 1.6$ & 0.891 & 0.837 \\
& $4-6$ & $3.5 \pm 1.4$ & 0.870 & 0.596 \\
& $7-12$ & $3.8 \pm 1.7$ & 0.898 & 0.756 \\
\hline
\end{tabular}

Abbreviations: SD, standard deviation; ICC, intraclass correlation coefficient; EI, emotional impact; FA, food anxiety; SDL, social and dietary limitation 


\section{Internal consistency}

Almost all of the results showed a Cronbach's a higher than 0.8 , except for the EI domain in the 4-6 age group, which showed a Cronbach's a 0.799. Among the age groups, the Cronbach's $a$ ranged from 0.927 to 0.967 . Among the 3 different domains, the Cronbach's a ranged from 0.799 to 0.919 . These results demonstrate excellent internal consistency of the FAQLQ-PF Thai version (Table 2).

\section{Discriminant validity}

No significant differences were observed between genders. Participants in the 7-12 age group had significantly higher global FAQLQ-PF and EI domain scores compared to the other 2 age groups. Also, participants who had duration of illness longer than 5 years had higher EI domain scores. Participants with anaphylaxis had a significantly higher global score (worse HRQL), and significantly higher EI, FA, and SDL domain scores compared to participants without anaphylaxis ( $p=0.006, p=0.015, p=0.025$, and $p=0.008$, respectively).
The number of implicated foods was also found to adversely affect patient quality of life. Participants with only 1 implicated food had significantly lower global FAQLQ-PF and SDL domain scores compared to participants with multiple implicated foods ( $p=0.011$ and $p=0.002$, respectively). Additionally, patients with respiratory symptoms had a significantly higher global score and significantly higher scores for the EI, FA, and SDL domains compared to participants without respiratory symptoms $(p=0.003, p=0.009, p=0.038$, and $p=0.001$, respectively). However and interestingly, there was no significant difference in global score between participants with and without cutaneous symptoms, gastrointestinal symptoms, and cardiovascular symptoms. Regarding the impact of reactions on HRQL, we found that patients that had less than 3 reactions/year had a significantly higher HRQL than those who had more than 3 reactions/year relative to global score and the EI, FA, and SDL domain scores $(p=0.002, p=0.002, p=$ 0.004 , and $p=0.004$, respectively).

Table 3. Discriminant validity of the Thai version of the Food Allergy Quality of Life Questionnaire-Parent Form (FAQLQ-PF)

\begin{tabular}{|c|c|c|c|c|c|c|c|c|c|}
\hline \multirow{2}{*}{ Characteristics } & \multirow{2}{*}{$\mathbf{N}(\%)$} & \multicolumn{2}{|c|}{ Global score } & \multicolumn{2}{|c|}{ EI score } & \multicolumn{2}{|c|}{ FA score } & \multicolumn{2}{|c|}{ SDL score } \\
\hline & & Mean & $p$-value & Mean & $p$-value & Mean & $p$-value & Mean & $p$-value \\
\hline \multicolumn{10}{|l|}{ Gender } \\
\hline Male & $45(50.0)$ & 3.8 & 0.418 & 3.9 & 0.660 & 4.3 & 0.377 & 3.4 & 0.417 \\
\hline Female & $45(50.0)$ & 4.0 & & 4.0 & & 4.6 & & 3.7 & \\
\hline \multicolumn{10}{|l|}{ Age (years) } \\
\hline $0-3$ & $30(33.3)$ & 3.5 & & 3.4 & & 4.3 & & 3.4 & \\
\hline $4-6$ & $30(33.3)$ & 3.8 & 0.651 & 3.9 & 0.242 & 4.2 & 0.958 & 3.5 & 0.933 \\
\hline $7-12$ & $30(33.3)$ & 4.4 & 0.045 & 4.5 & 0.003 & 4.7 & 0.371 & 3.8 & 0.474 \\
\hline \multicolumn{10}{|l|}{ Duration of illness } \\
\hline$<5$ years & $67(74.4)$ & 3.8 & 0.088 & 3.7 & 0.030 & 4.3 & 0.275 & 3.4 & 0.295 \\
\hline$>5$ years & $23(25.6)$ & 4.4 & & 4.5 & & 4.7 & & 3.8 & \\
\hline \multicolumn{10}{|l|}{ System involvement } \\
\hline \multicolumn{10}{|l|}{ Anaphylaxis } \\
\hline Yes & $22(24.4)$ & 4.6 & 0.006 & 4.6 & 0.015 & 5.1 & 0.025 & 4.3 & 0.008 \\
\hline No & $68(75.6)$ & 3.7 & & 3.7 & & 4.2 & & 3.3 & \\
\hline \multicolumn{10}{|l|}{ Cutaneous } \\
\hline Yes & $86(95.6)$ & 4.0 & 0.071 & 4.0 & 0.036 & 4.5 & 0.253 & 3.6 & 0.138 \\
\hline No & $4(4.4)$ & 2.7 & & 2.5 & & 3.6 & & 2.4 & \\
\hline \multicolumn{10}{|l|}{ Respiratory } \\
\hline Yes & $49(54.4)$ & 4.3 & 0.003 & 4.3 & 0.009 & 4.7 & 0.038 & 4.0 & 0.001 \\
\hline No & $41(45.6)$ & 3.5 & & 3.5 & & 4.1 & & 3.0 & \\
\hline \multicolumn{10}{|l|}{ Cardiovascular } \\
\hline Yes & $12(13.3)$ & 4.6 & 0.088 & 4.5 & 0.100 & 5.0 & 0.190 & 4.2 & 0.142 \\
\hline No & $78(86.7)$ & 3.8 & & 3.8 & & 4.4 & & 3.4 & \\
\hline
\end{tabular}


Table 3. (Continued)

\begin{tabular}{|c|c|c|c|c|c|c|c|c|c|}
\hline \multirow{2}{*}{ Characteristics } & \multirow{2}{*}{$\mathbf{N}(\%)$} & \multicolumn{2}{|c|}{ Global score } & \multicolumn{2}{|c|}{ EI score } & \multicolumn{2}{|c|}{ FA score } & \multicolumn{2}{|c|}{ SDL score } \\
\hline & & Mean & $p$-value & Mean & $p$-value & Mean & $p$-value & Mean & $p$-value \\
\hline \multicolumn{10}{|c|}{ System involvement (Continued) } \\
\hline \multicolumn{10}{|l|}{ Gastrointestinal } \\
\hline Yes & $28(31.1)$ & 4.2 & 0.245 & 4.1 & 0.423 & 4.7 & 0.352 & 3.9 & 0.146 \\
\hline No & $62(68.9)$ & 3.8 & & 3.8 & & 4.3 & & 3.4 & \\
\hline \multicolumn{10}{|c|}{ Frequency of reaction (times/year) } \\
\hline $1-3$ & $62(68.9)$ & 3.6 & 0.002 & 3.6 & 0.002 & 4.1 & 0.004 & 3.2 & 0.004 \\
\hline$>3$ & $28(31.1)$ & 4.6 & & 4.6 & & 5.1 & & 4.2 & \\
\hline \multicolumn{10}{|l|}{ Number of allergic foods } \\
\hline Single & $41(45.6)$ & 3.5 & 0.011 & 3.7 & 0.113 & 4.0 & 0.230 & 3.0 & 0.002 \\
\hline Multiple & $49(54.4)$ & 4.3 & & 4.1 & & 4.8 & & 4.0 & \\
\hline \multicolumn{10}{|l|}{ Oral immunotherapy } \\
\hline Yes & $6(6.7)$ & 4.9 & 0.068 & 5.0 & 0.061 & 5.2 & 0.234 & 4.6 & 0.073 \\
\hline No & $84(93.3)$ & 3.9 & & 3.9 & & 4.4 & & 3.5 & \\
\hline
\end{tabular}

A $p$-value $<0.05$ indicates statistical significance

Abbreviations: EI, emotional impact; FA, food anxiety; SDL, social and dietary limitation

Concerning the type of food allergy, participants who were allergic to wheat had significantly worse HRQL in all scoring categories (global FAQLQ-PF score, and EI, FA, and SDL domain scores) than participants who were not allergic to wheat ( $p=0.002, p=0.020, p=0.001$, and $p=0.002$, respectively). In addition, participants who were allergic to shellfish had a higher score in the EI domain than participants who were not allergic to shellfish $(p=0.045)$. No statistically significant differences were observed between participants with and without treenut allergy, peanut allergy, egg allergy, or milk allergy (Table 4a). Also, no statistically significant difference was observed between patients who received oral immunotherapy (OIT) and those who did not receive OIT

\section{Table 4a. Discriminant validity among different kinds of food.}

\begin{tabular}{|c|c|c|c|c|c|c|c|c|c|}
\hline \multirow{2}{*}{ Characteristics } & \multirow{2}{*}{$\mathbf{N}(\%)$} & \multicolumn{2}{|c|}{ Global score } & \multicolumn{2}{|c|}{ EI score } & \multicolumn{2}{|c|}{ FA score } & \multicolumn{2}{|c|}{ SDL score } \\
\hline & & Mean & $p$-value & Mean & $p$-value & Mean & $p$-value & Mean & $p$-value \\
\hline \multicolumn{10}{|l|}{ Type of allergic food } \\
\hline \multicolumn{10}{|l|}{ Wheat } \\
\hline Yes & $34(37.8)$ & 4.5 & 0.002 & 4.4 & 0.020 & 5.1 & 0.001 & 4.2 & 0.002 \\
\hline No & $56(62.2)$ & 3.6 & & 3.7 & & 4.0 & & 3.2 & \\
\hline \multicolumn{10}{|l|}{ Milk } \\
\hline Yes & $29(32.2)$ & 3.8 & 0.472 & 3.6 & 0.146 & 4.1 & 0.208 & 3.7 & 0.461 \\
\hline No & $61(67.8)$ & 4.0 & & 4.0 & & 4.6 & & 3.5 & \\
\hline \multicolumn{10}{|l|}{ Egg } \\
\hline Yes & $29(32.2)$ & 4.0 & 0.808 & 3.9 & 0.961 & 4.5 & 0.931 & 3.7 & 0.359 \\
\hline No & $61(67.8)$ & 3.9 & & 3.9 & & 4.4 & & 3.4 & \\
\hline \multicolumn{10}{|l|}{ Peanuts } \\
\hline Yes & $11(12.2)$ & 4.5 & 0.113 & 4.5 & 0.175 & 4.9 & 0.246 & 4.4 & 0.061 \\
\hline No & 79 (87.8) & 3.8 & & 3.9 & & 4.4 & & 3.4 & \\
\hline
\end{tabular}


Table 4a. (Continued)

\begin{tabular}{|c|c|c|c|c|c|c|c|c|c|}
\hline \multirow{2}{*}{ Characteristics } & \multirow{2}{*}{ N (\%) } & \multicolumn{2}{|c|}{ Global score } & \multicolumn{2}{|c|}{ EI score } & \multicolumn{2}{|c|}{ FA score } & \multicolumn{2}{|c|}{ SDL score } \\
\hline & & Mean & $p$-value & Mean & $p$-value & Mean & $p$-value & Mean & $p$-value \\
\hline \multicolumn{10}{|c|}{ Type of allergic food (Continued) } \\
\hline \multicolumn{10}{|l|}{ Treenuts } \\
\hline Yes & $14(15.6)$ & 4.4 & 0.148 & 4.3 & 0.297 & 4.9 & 0.194 & 4.2 & 0.112 \\
\hline No & 76 (84.4) & 3.8 & & 3.9 & & 4.4 & & 3.4 & \\
\hline \multicolumn{10}{|l|}{ Shellfish } \\
\hline Yes & $42(46.7)$ & 4.1 & 0.103 & 4.2 & 0.045 & 4.5 & 0.406 & 3.8 & 0.223 \\
\hline No & $48(53.3)$ & 3.7 & & 3.7 & & 4.3 & & 3.3 & \\
\hline
\end{tabular}

A $p$-value $<0.05$ indicates statistical significance

Abbreviations: EI, emotional impact; FA, food anxiety; SDL, social and dietary limitation

Table 4 b. Discriminant validity of wheat allergy with and without anaphylaxis

\begin{tabular}{|c|c|c|c|c|c|c|c|c|c|}
\hline \multirow{2}{*}{ Characteristics } & \multirow{2}{*}{$\mathbf{N}(\%)$} & \multicolumn{2}{|c|}{ Global score } & \multicolumn{2}{|c|}{ EI score } & \multicolumn{2}{|c|}{ FA score } & \multicolumn{2}{|c|}{ SDL score } \\
\hline & & Mean & $p$-value & Mean & $p$-value & Mean & $p$-value & Mean & $p$-value \\
\hline With anaphylaxis & 10 & 4.7 & 0.460 & 4.7 & 0.450 & 5.2 & 0.725 & 4.3 & 0.714 \\
\hline Without anaphylaxis & 24 & 4.4 & & 4.2 & & 5.1 & & 4.1 & \\
\hline
\end{tabular}

A $p$-value $<0.05$ indicates statistical significance

Abbreviations: EI, emotional impact; FA, food anxiety; SDL, social and dietary limitation

\section{Discussion}

The objective of this study was to lingually and culturally translate the FAQLQ-PF Thai version, and to validate its benefit for assessing the HRQL of Thai pediatric population with food allergy via information provided by their parents. The fact that $90 \%$ of parents were able to completely answer the questionnaire the first time indicates a high level of feasibility. The reliability of the FAQLQ-PF Thai version was evaluated by intraclass correlation coefficient (ICC) via the test-retest method. The ICCs for the 0-3, 4-6, and 7-12 age groups were $0.868,0.604$, and 0.811 , respectively. The ICCs for the 3 different domains showed a value higher than 0.75 in the $0-3$ and 7-12 age groups, while the ICCs in the 4-6 age group ranged from 0.52 to 0.62 . The lower ICCs observed in the 4-6 age group may be due to the fact that only 14 or 30 caregiver completed the FAQLQ-PF Thai version a second time. However, ICCs within the range of 0.5 to 0.75 are considered to represent moderate reliability. ${ }^{24,25}$ In terms of internal consistency, the Cronbach's a ranged from 0.799 to 0.967 , which indicates very high to excellent internal consistency.

Discriminant validity showed that the older age group had lower quality of life (higher FAQLQ-PF score). This result is similar to the results of previous studies conducted in Europe, the US, and Japan. ${ }^{19,22}$ However, statistical significance was observed only for the global FAQLQ-PF score and the EI domain in the 7-12 age group. This might be explained by the fact that older children are engaged in more social activities without being chaperoned by their parents/caregivers, such as attending school or parties, and these activities might be limited by their food allergy condition. The frequency of reactions and the presence of anaphylaxis and respiratory symptoms were found to adversely influence HRQL, as shown in the total score and in all domains. This is similar to the findings of a study from Japan that found that patients with anaphylaxis had significantly higher scores for the total score and all domains than patients without anaphylaxis. ${ }^{22}$ In contrast, there was no statistical significant difference in scores was observed between patients with and without anaphylaxis in a study from Spain. ${ }^{20}$ In the present study, participants with a single implicated food had significantly better HRQL than those with multiple implicated foods relative to total score and the SDL domain. This result correspond to the studies from the US and Europe. ${ }^{19}$ However, the number of implicated foods did not significantly affect HRQL in the Japanese ${ }^{22}$ and Spanish studies. ${ }^{20}$ We also found the type of allergic food to be related to HRQL. Importantly, we found wheat allergy to be significantly associated with lower HRQL compared to other foods. The effect in HRQL was no statistical significance between those who present and absent of history of anaphylaxis (Table $\mathbf{4 b}$ ). Also, from the regression analysis showed that wheat allergy affected the quality of life in global score, FA and SDL domain ( $p=0.011, p=0.005$, $p=0.011$ respectively). Whereas, the presence of anaphylaxis had an effect only in the global score and SDL domain ( $p=$ $0.032, p=0.041$ respectively) (Table 5). The cause that wheat allergy had significant effect in FA score can be explained by the fact that wheat is a common ingredient in many kinds of food, so these patients are much more limited in the types of foods they are able to eat. In contrast, the previously described study from Spain found food allergy to eggs, milk, or nuts had effect on the EI score. ${ }^{20}$ However, there was no report about wheat allergy in the Spanish study. ${ }^{20}$ 
Table 5. Regression analysis of Wheat allergy and Anaphylaxis

\begin{tabular}{|c|c|c|c|c|c|c|c|c|c|}
\hline \multirow[b]{2}{*}{ Characteristics } & \multirow[b]{2}{*}{$\mathbf{N}(\%)$} & \multicolumn{2}{|c|}{ Global score } & \multicolumn{2}{|c|}{ EI score } & \multicolumn{2}{|c|}{ FA score } & \multicolumn{2}{|c|}{ SDL score } \\
\hline & & $\begin{array}{l}\text { Regression } \\
\text { Coefficeint }\end{array}$ & $p$-value & $\begin{array}{l}\text { Regression } \\
\text { Coefficeint }\end{array}$ & $p$-value & $\begin{array}{l}\text { Regression } \\
\text { Coefficeint }\end{array}$ & $p$-value & $\begin{array}{l}\text { Regression } \\
\text { Coefficeint }\end{array}$ & $p$-value \\
\hline Wheat allergy & 34 & 0.756 & 0.011 & 0.552 & 0.071 & 0.928 & 0.005 & 0.857 & 0.011 \\
\hline Anaphylaxis & 22 & 0.716 & 0.032 & 0.675 & 0.050 & 0.574 & 0.119 & 0.770 & 0.041 \\
\hline
\end{tabular}

A $p$-value $<0.05$ indicates statistical significance

Abbreviations: EI, emotional impact; FA, food anxiety; SDL, social and dietary limitation

We also found that patients who receiving oral immunotherapy (OIT) had no significant different in HRQL when compare to those who avoid the affected food. The reason might be explained by a small number of patients who underwent OIT. The HRQL might obviously be seen if we compare it before and after the OIT.

The limitations of our study include we have too small numbers of caregivers of 4-6 age group who returned the questionnaire at the second times. Therefore, the ICCs might be lower than expected.

In conclusion, we successfully developed a lingual and cultural translation of the FAQLQ-PF into Thai language, and we used it to demonstrate the influence of different factors on HRQL among food allergic pediatric Thai population. Our results show that the FAQLQ-PF Thai version is a valid and reliable tool for evaluating the HRQL of Thai children with food allergy. This tool can be used by clinicians to objectively assess and follow-up food allergic patients as an adjunct to history taking, physical examination, and laboratory investigation.

\section{Acknowledgements}

The authors gratefully acknowledge Prof. Dr. Audrey DunnGalvin for granting us permission to translate the FAQLQ-PF to Thai language; the translators and parent participants for assisting with the development of the FAQLQ-PF Thai version; and, Miss Julaporn Pooliam for assistance with statistical analysis.

\section{Conflict of interest declaration}

All authors declare no personal or professional conflicts of interest relating to any aspect of this study.

\section{Funding disclosure}

This was an unfunded study.

\section{References}

1. Sicherer SH, Sampson HA. Food allergy: A review and update on epidemiology, pathogenesis, diagnosis, prevention, and management. J Allergy Clin Immunol. 2018;141:41-58.

2. Jackson KD, Howie LD, Akinbami LJ. Trends in Allergic Conditions Among Children [Internet]. United States: NCHS data brief; 2013 [cited 2020 Jan 10]. Available from: https://www.cdc.gov/nchs/data/databriefs/db121.pdf

3. Santadusit S, Atthapaisalsarudee S, Vichyanond P. Prevalence of adverse food reactions and food allergy among Thai children. J Med Assoc Thai. 2005;88 Suppl 8:S27-32.

4. Lao-araya M, Trakultivakorn M. Prevalence of food allergy among preschool children in northern Thailand. Pediatr Int. 2012;54:238-43.
5. Abrams EM, Sicherer SH. Diagnosis and management of food allergy. CMAJ. 2016;188:1087-93

6. Cummings AJ, Knibb RC, King RM, Lucas JS. The psychosocial impact of food allergy and food hypersensitivity in children, adolescents and their families: a review. Allergy. 2010;65:933-45.

7. Ravid NL, Annunziato RA, Ambrose MA, Chuang K, Mullarkey C, Sicherer $\mathrm{SH}$, et al. Mental health and quality-of-life concerns related to the burden of food allergy. Immunol Allergy Clin North Am. 2012;32:83-95.

8. Cohen BL, Noone S, Munoz-Furlong A, Sicherer SH. Development of a questionnaire to measure quality of life in families with a child with food allergy. J Allergy Clin Immunol. 2004;114:1159-63.

9. Kajornrattana T, Sangsupawanich P, Yuenyongviwat A. Quality of life among caregivers and growth in children with parent-reported food allergy. Asian Pac J Allergy Immunol. 2018;36:22-26.

10. Antolin-Amerigo D, Manso L, Caminati M, de la Hoz Caballer B, Cerecedo I, Muriel A, et al. Quality of life in patients with food allergy. Clin Mol Allergy. 2016;14:4.

11. Ingerski LM, Modi AC, Hood KK, Pai AL, Zeller M, Piazza-Waggoner C, et al. Health-related quality of life across pediatric chronic conditions. J Pediatr. 2010;156:639-44.

12. Bai G, Herten MH, Landgraf JM, Korfage IJ, Raat H. Childhood chronic conditions and health-related quality of life: Findings from a large population-based study. PLoS One. 2017;12:e0178539.

13. Flokstra-de Blok BM, van der Velde JL, Vlieg-Boerstra BJ, Oude Elberink JN, DunnGalvin A, Hourihane JO, et al. Health-related quality of life of food allergic patients measured with generic and disease-specific questionnaires. Allergy. 2010;65:1031-8.

14. Flokstra-de Blok BM, DunnGalvin A, Vlieg-Boerstra BJ, Oude Elberink JN, Duiverman EJ, Hourihane JO, et al. Development and validation of a self-administered Food Allergy Quality of Life Questionnaire for children. Clin Exp Allergy. 2009;39:127-37.

15. Eiser C, Morse R. Quality-of-life measures in chronic diseases of childhood. Health Technol Assess. 2001;5:1-157.

16. Eiser C, Morse R. A review of measures of quality of life for children with chronic illness. Arch Dis Child. 2001;84:205-11.

17. DunnGalvin A, Cullinane C, Daly DA, Flokstra-de Blok BM, Dubois AE, Hourihane JO. Longitudinal validity and responsiveness of the Food Allergy Quality of Life Questionnaire - Parent Form in children 0-12 years following positive and negative food challenges. Clin Exp Allergy. 2010;40:476-85.

18. DunnGalvin A, de BlokFlokstra BM, Burks AW, Dubois AE, Hourihane JO. Food allergy QoL questionnaire for children aged 0-12 years: content, construct, and cross-cultural validity. Clin Exp Allergy. 2008;38:977-86.

19. DunnGalvin A, Koman E, Raver E, Frome H, Adams M, Keena A, et al. An Examination of the Food Allergy Quality of Life Questionnaire Performance in a Countrywide American Sample of Children: Cross -Cultural Differences in Age and Impact in the United States and Europe. J Allergy Clin Immunol Pract. 2017;5:363-8.

20. Manso L, Pineda R, Huertas B, Fernandez-Rivas M, Dieguez MC, Cerecedo I, et al. Validation of the Spanish Version of the Food Allergy Quality of Life Questionnaire-Parent Form (S-FAQLQ-PF). J Investig Allergol Clin Immunol. 2017;27:363-9.

21. Couto M, Silva D, Piedade S, Borrego L, Flokstra-de Blok B, Dunn Galvin A, et al. Translation to Portuguese and cultural adaptation of Food Allergy Quality of Life Questionnaire - Parent Form (FAQLQ-PF). Eur Ann Allergy Clin Immunol. 2016;48:82-7.

22. Mizuno Y, Ohya Y, Nagao M, DunnGalvin A, Fujisawa T. Validation and reliability of the Japanese version of the Food Allergy Quality of Life Questionnaire-Parent Form. Allergol Int. 2017;66:290-5. 
23. World Health Organization [Internet]. Geneva: Process of translation and adaptation of instruments; c2020 [cited 2020 Jan 10]. Available from: https://www.who.int/substance_abuse/research_tools/translation/en/.

24. Koo TK, Li MY. A Guideline of Selecting and Reporting Intraclass Correlation Coefficients for Reliability Research. J Chiropr Med. 2016; 15:155-63.
25. Perinetti G. StaTips Part IV: Selection, interpretation and reporting of the intraclass correlation coefficient. South Eur J Orthod Dentofac Res. 2018;5:3-5. 